\title{
CREATIVE RECONSTRUCTIONS OF POLITICAL IMAGERY IN AN INSTAGRAM-BASED ELECTION CAMPAIGN: IMPLICATIONS FOR VISUAL RHETORICAL LITERACY
}

\author{
Katarzyna MOLEK-KOZAKOWSKA (D) 1,2*, Agnieszka KAMPKA (D) ${ }^{3}$ \\ ${ }^{1}$ Institute of Linguistics, University of Opole, pl. Kopernika 11, 45-040 Opole, Poland \\ ${ }^{2}$ Department of Creative Communication, Faculty of Creative Industries, \\ Vilnius Gediminas Technical University, Traku str. 1, 01132 Vilnius, Lithuania \\ ${ }^{3}$ Institute of Social Sciences and Pedagogy, Warsaw University of Life Sciences, \\ Nowoursynowska 166, 02-787 Warsaw, Poland
}

Received 5 November 2020; accepted 16 May 2021

\begin{abstract}
This article reviews literature on visual rhetoric in political campaigning and synthesizes several strands of current research devoted to the rhetorical potential of communicating with visuals in online environments. It uses rhetorical concepts of identification and manoeuvring, as well as the category of topos, to discuss the implications of an abductive analysis of a coded corpus of 1976 Instagram images posted during 2019 election to the European Parliament campaign in Poland. On this basis, the article offers recommendations related to the awareness of topo $i$ in visual rhetoric to foster users' creative inventory. In the context of increasingly strategically designed and creative online political communications, scholarship should offer guidance on how to parse images according to how they (mis)represent political reality to fit the purposes of elite communicators, and how to challenge them.
\end{abstract}

Keywords: creative reconstruction, Instagram, political campaign, rhetorical literacy, topos, visual manoeuvring.

\section{Introduction}

By analogy to media literacy (Livingstone, 2004), visual literacy is the ability to find, access, analyze and use images, be they photos, videos, animations or infographics, efficiently and responsibly for the purposes of study, work, and civic action. Rhetorical visual literacy would also include the ability to parse imagery in order to identify the persuasive potential of visual affordances used to express arguments and stances in the public domain (Conole \& Dyke, 2004). The advent of social media has brought new tools to construct political messages out of well-known schemas. Hence, visual rhetorical literacy - as a set of complex competences now extends to the domains of artistic creativity and media-savviness. It also requires a specific

\footnotetext{
${ }^{\star}$ Corresponding author. E-mail: molekk@uni.opole.pl
} 
knowledge of means of visual persuasion, and the willingness to apply critical thinking even to the most mundane types of visual input (Janks, 2010). In the current media-saturated world and the culture of visual distractions, such competences have become one's "equipment for living", to borrow a phrase from the philosopher and rhetorician Burke (1969).

This article reviews the literature on visual persuasion in political communication and synthesizes several strands of current research devoted to the rhetorical potential of photographic images. We revisit conclusions of recent empirical studies of visual persuasion in mediated political campaigning (section 1). Then we propose a method to attend to "visual manoeuvring" in photography through reconstruction of topoi (section 2). For the sake of illustration of the argument, we discuss implications from an analysis of 1976 photographs garnered from official Instagram profiles of political candidates during the 2019 election to the European Parliament (EP) campaign in Poland (section 3). In the discussion, we identify the patterns of photographic self-representation on Instagram that are creatively mobilized for the purposes of online campaigning. In the conclusion, the study reflects on how these patterns might enhance (or, by contrast, discourage) political deliberation (Warnick \& Heineman, 2012), given the rising role of image-prevalent social media (Fenton \& Barassi, 2011; Seo, 2014).

To weave together the arguments and to structure the analysis, the article relies on Burke's (1969) concept of identification to map how political campaigners design messages with regard to voters' needs for group identity and communal values. Visual processing spawned by social media requires a reorganization of known arguments to strategically match new affordances, which van Eemeren and Houtlosser (1999) call strategic manoeuvring. Hence, we trace how online self-representations are creatively constructed by political communicators to build a positive image, garner larger voter support, or legitimize political purposes. The analysis makes use of the classical concept of topos in order to tease out the persuasive tension between the repetitiveness and the creativeness of argumentative schemas in visual representations. McKeon, for example, sees topoi as a storehouse of "the familiar" used as

"instruments for the perception, creation, arrangement, and establishment of the new in existence, experience, discursive exploration, and inclusive organization" (1973, p. 210).

For McKeon, rhetoric (and rhetorical literacy) is not just a craft of recycling established schemas, but mainly the art of innovating and reconstructing symbolic worlds to match new existential challenges.

In each section, we make recommendations regarding public awareness of "visual manoeuvring" to enhance visual rhetorical literacy. In this, we do not aim to criminalize visual means of political communication. Instead, we acknowledge that, particularly in the context of online political campaigning, parsing images according to how they tend to (mis) represent political reality is important. We are not oblivious to the multitude of creative, pro-democratic uses of images in online political communication; neither do we assume a completely visually and rhetorically illiterate public. However, with the advent of new visualization technologies, new research on psychology of media influence, or new strategies of targeting through algorithms, the general public may not have much chance to resist this manoeuvring in political campaigning. 


\section{Visual persuasion in theory and practice of political communication}

There are a few strands of inquiry related to how images, particularly those disseminated via Internet technologies, could be subjected to a rhetoric-oriented research. Some open new fields of study, identify new relevant objects of scrutiny, or offer implications for a more robust civics education and literacy studies. Yet, the unique rhetorical power of imagery, according to Ott and Dickinson (2009), is still in need of being sufficiently addressed in terms of combining theory, rhetorical criticism and recommendation. We also aim to apply the tools of rhetorical scholarship "to evaluate the civic role of public images", and particularly to trace the creative "visual framing of everydayness" in the political (Ott \& Dickinson, 2009, p. 393). In this section we introduce the following aspects relevant to exploring creative visual persuasion: the culture of visual distraction, online visual manipulation, visual construction of political leadership and state, visual amplification of political confrontation, and visual aesthetic conventions.

DeLuca (2006) insists that rhetorical scholars should build a new framework for visual persuasion fit for new media: one in which speed and imminence dominate in the torrent of impressions that invite "distraction not contemplation". For him, the glances typical of distraction have become the "necessary form of perception" in the technology-driven world of contemporary public spheres (DeLuca, 2006, p. 89). It would be indeed misguided to continue studying contemplation while the public engages in distraction, and perhaps needs a new set of skills for deciphering visual persuasion (Messaris, 2012). For example, social media channels are said to inundate us with trivial user-generated content (Warnick \& Heineman, 2012), but is this content really devoid of rhetoric? How do we deal with stock photography that is easy to reuse to achieve trending in social networks (Frosh, 2002), or photo-shopped photographs and computer generated photo-realistic images (Lehmuskallio et al., 2019)? By itself, such heavy exposure to images, even if the fraudulent and manipulative ones still constitute a fraction of political content (Mourão \& Robertson, 2019), cultivates new visual literacy practices.

In the context of political communication, researchers are involved in scrutinizing how images are capable of persuading viewers to the legitimacy of political leaders' purposes. A classic example of applying a rhetorical framework to visuals in political communication is Erickson's (2000) study on representations of United States (US) presidents' performance through photography. By analyzing both historical and current materials, Erickson critiques the hegemonic forces that operate in visual representations of elected officials, who end up "governing by illusions" (2000, p. 156). This has implications for considering how officially disseminated photography might in fact mystify political purposes, bypass the public forum, serve partisan interests and misdirect citizens' attention (cf. Veneti et al., 2019). Such research becomes particularly urgent at a time when images are creatively manipulated (as memes) and disseminated at low cost and on mass scale through social media platforms (with bots).

Parallel to the rise of a "rhetorical" office, Sheridan et al. (2005) point to the rise of "rhetorical events" that have replaced public speeches. They see the need to supplant the analyses of deliberation with more insights from (pop)cultural analysis. This concerns the attention to political uses of cultural grand narratives and their heroes/villains or winners/losers, as 
deliberation and confrontation often co-exist in the media (tele)visual landscape. The visual presentations of political stories, notably the filmic conventions used in campaigning, require a careful parsing of visual claims to factuality, much in the same way as verbal messages do. In consequence, the public's cultivation into certain visually potent narratives of state indolence or leaders' corruption is correlated with the rise of political populism (Phillips, 2018). Meanwhile, the "civic voice" of the public tends to be lost in such narratives, since online imaginaries constantly elevate the leaders in dramatic situations at the expense of the portrayal of citizens in everyday circumstances (Tuunanen \& Hirsto, 2018).

As regards amplifying visual confrontation and drama, Edwards (2012) explores how election debates are covered to foreground the oppositional positioning of candidates in a political spectacle that "sells well" and attracts attention. Indeed, there are some common visualization strategies that are routinely deployed to: (1) intensify political clash (with contrasting profiles, face-off poses); (2) neutralize positions (with standardization of selfpresentations); (3) introduce false symmetries (with mirroring footing, level, camera perspectives); or (4) demonize the opponent (with partisan media manipulating the imagery to the detriment of one candidate). The interrogation of such visual editing techniques should be included in literacy training to shed light on how social division is achieved. In addition, Driessens et al. (2010) have shown that entertainment-driven media logics require politicians to adopt techniques of personalization - from emphasizing their individual position within the party to strategically revealing personal details to keep the public engaged.

Further exploration of visualization strategies is taken up by Ravelli and van Leeuwen (2018) regarding "modality" - the perceived realism and attributed fact-value. With photo affordances that allow not only more realistic ensembles (e.g., Adobe Photoshop and deepfake), but also more symbolic and artful representations, there comes a reflection on how to approach visual metaphors or visual simulations. For example, black-and-white photographic filters can be used to "historicize contemporary images", or how enhanced colors can "connote fantasy worlds". Apart from color filters, visual manipulation software can used for other effects - cropping and recontextualization in a new setting, illumination and contrast to redirect attention, depth and articulation of detail to allow sensory stimulation, or movement in GIF animation to introduce agency. Ravelli and van Leeuwen (2018) point to the implications of online visualization strategies and their potential to "manufacture" factuality or history (documentaries), affect or romanticism (postcards, music videos, cartoons), authority (Prezi, Microsoft PowerPoint), or neoliberal practices of consumption (marketing catalogues, shopping websites). Meanwhile, social platform trending and arranged search engine returns may lead to naturalizing some ideology-laden representations at the expense of a variety of points of view (Dan \& Arendt, 2021).

\section{A method for studying visual persuasion in photography}

Studies of visuals as elements of social networking in political campaigning are often aimed at identifying the creative resources used to promote (or, by contrast, to discourage) deliberation in the public sphere (cf. Warnick \& Heineman, 2012). However, to offer implications for visual literacy, it is important to work within a methodological frame that is not only clearly 
articulated but also non-reductionist, given that visual communication is much more diffuse and unstructured than verbal communication. Indeed, in argumentation theory, there is an ongoing debate whether there indeed are "visual arguments" in photographs (Champagne \& Pietarinen, 2020). In this section we calibrate our approach by bringing together two wellknown frameworks that can enhance the task of mapping visual persuasion in political campaigning. One can account for the visual content chosen to target audience's preferences, and the other for the formal properties of strategic visualization.

We start by explaining the usefulness of Burke's (1969) concept of "identification" and operationalizing it for our coding of visual material. Then we consider how to adapt van Eemeren's and Houtlosser's (1999) "strategic manoeuvring" to visual analysis. We assume that breaking complex imaginaries down to specific properties allows us to grasp the interplay between patterns of creativity and predictability. The catalogue of categories that enable our tracing of photo affordances has been marked in italics below.

First, the concept of identification can be appropriated to showing how political agents adjust their visual persuasion techniques to the target audience's needs. In Burke's rhetorical theory (1969, pp. 20-22), identification is instantiated in any act of persuasion in which the self must identify with - or be in some way like - another entity, to accept its motives. Rhetorical expression, for Burke, is the linguistic and mental work oriented to overcoming divisions, strife and egoistic motives. Having "common terministic screens" and "shared forms of expressions" to label issues means participating in a common framework for the understanding of reality. By the same token, we claim that, in political communication, certain conventional photographic representations that reproduce society's imaginaries are used to trigger identification with dominant perspectives, values or ideologies. In the end, they guide the viewer to accept the motives of the political communicator. As a result, the close analysis of visual representations of significant social actors ("us"/"them"), their actions and attributes, inferred motives and circumstances in our coding categories (subsection 3.2) helps us to trace how identification is enacted anew, this time for a new public of social media users.

Multimodal discourse analysts have already broken down the analysis of visual representations to several variables regarding photo affordances used for identification. For example, Machin (2007, pp. 110-122) discusses how the viewer can be positioned to align with the ideas, actions and participants presented in photos through gaze, angle of interaction, or distance, as well as through ways of categorizing social actors and endowing them with agency. In another study, Borgerson and Schroeder (2005) have demonstrated that pictorial face-ism (e.g., representations of celebrities), complete with idealization of the body and exclusion of dissonance (e.g., minority), tends to be strategically applied in promotional discourses. These choices aim to achieve customer identification with products, services or brands. Researchers also point to the role of recycled stock photography (Frosh, 2002) in the context of leading consumers into proscribed interpretations, and making them succumb to fantasies. Such means of creative "manufacturing of identification" are at odds with a rational reception of political persuasion, and should thus be treated as an important aspect of visual literacy.

Next, we want to account methodologically for the strategic element of visual political communication, derived from the notion of manoeuvring by van Eemeren and Houtlosser (1999). Although primarily developed to evaluate exchanges of arguments in verbal 
communication, their pragma-dialectic theory of argumentation has fostered an interesting spinoff: the category of "strategic manoeuvring", which acknowledges that weaker arguments can in fact be creatively enhanced through rhetorical means (van Eemeren \& Houtlosser, 2009). It is not uncommon for political campaigners to apply specific "visualization strategies" to superimpose factuality, confrontation, dramatization, narrativity or personalization cues on photographic affordances. Some of them involve topoi - easily recognized schemas for presentations of elements of political reality, such as activities, circumstances or institutions (McKeon, 1973). This can be done, for example, by appropriations of photo-ops, celebrity, cultural scripts and stock imagery. campaigners also resort to figurative tropes (national symbolism, pictorial metaphor) that emotionalize or aestheticize the appeal. Visual manoeuvring might involve certain aesthetic, iconographic or compositional enhancements and modalities (Ravelli \& van Leeuwen, 2018) that collect attention and bypass reasoning to produce affective responses, or even push the viewers into fallacious conclusions, if consumed unreflexively within the culture of visual distraction.

\section{Instagram photography in Polish election to the European Parliament campaign}

To illustrate how to apply this method for identifying online visual manoeuvring through analysis of photographs, we present insights from a case study of a recent campaign in Poland (Kampka \& Molek-Kozakowska, 2020), which is based on data from Instagram profiles of political candidates during the 2019 EP campaign. Although it is contextualized within one national public sphere, we offer empirically verified observations and interpretations of emerging patterns that have implications for visual literacy elsewhere. First we introduce the Polish context of Instagram use for political campaigning (subsection 3.1) and describe our sampling and coding procedures to show our applications of categories explained above (subsection 3.2). Then we move from description of our results (subsection 3.3) to the larger implications of creative inventories that should be considered for enhancing visual rhetorical literacy of political campaigning (subsection 3.4).

\subsection{Instagram as a venue for political campaigning}

Instagram's technical affordances prioritize photographs, which can be accompanied with captions and cross-referenced to hashtags as well as opened to commentary. Instagram has been used effectively by presidential candidates in the US and across Europe (as reported after each campaign by e.g., Nielsen surveys and Pew Research Center reports), and is increasingly colonized by institutions and companies for the purposes of self-promotion. Instagram-based campaigning allows posting frequent and instantaneous updates cheaply and might target individuals that do not follow politics in the mainstream media. In Poland, at the time of the EP campaign, Instagram users constituted about $17 \%$ of the population, and the majority (65\%) were between 18 and 34 years old. Yet, when looking at concurrent trends in popularity (football, fitness, fashion, celebrities, photography, places, gaming), political figures and parties do not constitute a significant percentage of following or engagement (NapoleonCat, 2019). Nevertheless, since all the major parties and many public officials had already been 
present on Instagram during the previous domestic election campaigns in Poland, it is useful to explore this new area to establish emerging visual manoeuvres.

\subsection{Sampling and coding}

As of 2019, there have been 13 European Union (EU) electoral constituencies in Poland and six committees registered for the EP in each of them: Law and Justice (in Polish: Prawo $i$ Sprawiedliwość) - the conservative ruling party; European Coalition (in Polish: Koalicja Europejska) - a pro-European coalition of centrist and liberal parties with social democrats and greens; Spring (in Polish: Wiosna) - a newly established progressive party; The Left (in Polish: Lewica) - a coalition of various left-wing parties; Kukiz'15 - a Christian-democratic party; and National Movement (in Polish: Ruch Narodowy) - a collection of national, right-wing fringe groups. The Instagram profiles of six top candidates from each of the six committees were monitored between 16th April (official Nomination Day) and 26th May (election day) in 2019 to get a representative sample of photographic material.

In the second stage of sampling, three most active candidates from each election committee were followed and their posts pooled into a corpus comprising 1976 photos (the few graphics, films and Insta-stories published were excluded from the sample as numerically unrepresentative). This corpus of images was then coded by four coders according to a coding scheme that included salient variables of representation of candidates interlinking with categories operationalized above:

- Does the candidate feature in the photo? (yes/no) - visibility, face-ism;

- What logos/symbols are used? (e.g., European/Polish/party) - political identification/ alignment ("us");

- What is the default role assumed by the candidate? (e.g., official/common person/ celebrity/family member) - social categorization/agency;

- What is the action performed by the candidate? (e.g., rallying/speech-making/ shaking hands/posing for the photo) - performance/leadership construction;

- Who accompanies the candidate? (e.g., family/politicians/common people/the youth/ the elderly/the disadvantaged/journalists/celebrities/service-people/folk people/the campaign team) - social identification/community;

- What is the event/entity/setting represented? (e.g., campaign rally/meeting with voters/official state ceremony/press conference/work/religious rituals/culture events/nature) - stock imagery/topoi;

- What compositional/publishing techniques are used? (e.g., single photo/photo gallery/ selfie/repost from other media/abstract representation) - aesthetics/dissemination.

\subsection{Results}

The following presentation includes our interpretation of emerging patterns of political campaigning in relation to: Instagram's photographic affordances, the dominant profile types, party-specific presentational strategies, individual self-promotion techniques and identitybased persuasion, as well as the uses of stock imagery, particularly, various ideology-laden topoi. We focus on the questions if and how these topoi are creatively reconstructed in the new medium of Instagram. 
First of all, we note that the original function of Instagram (to share private moments and connect with friends) has been backgrounded, as most candidates relatively rarely present themselves in private settings. As having an Instagram profile is increasingly an expectation from a public official or a political challenger, some candidates seem to navigate the gap between their private persona and the public photo-op-like content with some difficulty. For example, they intertwine political campaign messages with unedited selfies or aestheticized photos of themselves in everyday/family settings, or just keep a visual record of their routine activities (e.g., moments on the campaign trail). This might be a strategic manoeuver to manufacture identification or to diminish the distance between the party and the voting public to mitigate the gap inherent in official portraiture.

Another insight regarding the networking affordances used is that the collected Instagram posts rarely contain references to other media and generally lack hashtags. In this respect most of the posts have failed to produce a wave effect that could reach people who do not follow particular politicians, but who could come across their messages through popular hashtags, trending, re-posts or other means. Instead, the candidates restricted themselves to promoting the events or shows they attended, and linked to podcasts and articles that were published about them or on party webpages. On one hand, this could point to a certain lack of media-savviness on the part of the campaigners, but on the other, it could also be a strategic decision to keep loyal followers attending to the posts without distractions, in an effort to make them act as political opinion leaders for their networks with time.

Despite the variety of profile formats and the wide discrepancies in the number of photos posted by leading candidates, it is possible to distinguish several typical patterns of visual self-promotion. The most dominant type seems to be an official profile, most probably set up and updated by the candidate's team, where the posted images show the candidate campaigning (or, if he/she holds a public office, at work). The majority of the photos are taken in a professional manner (high quality, good photogenic parameters, balanced composition), and there is an acute lack of personal material (no selfies) suggesting the official "topos of the party nominee" (Figure 1).

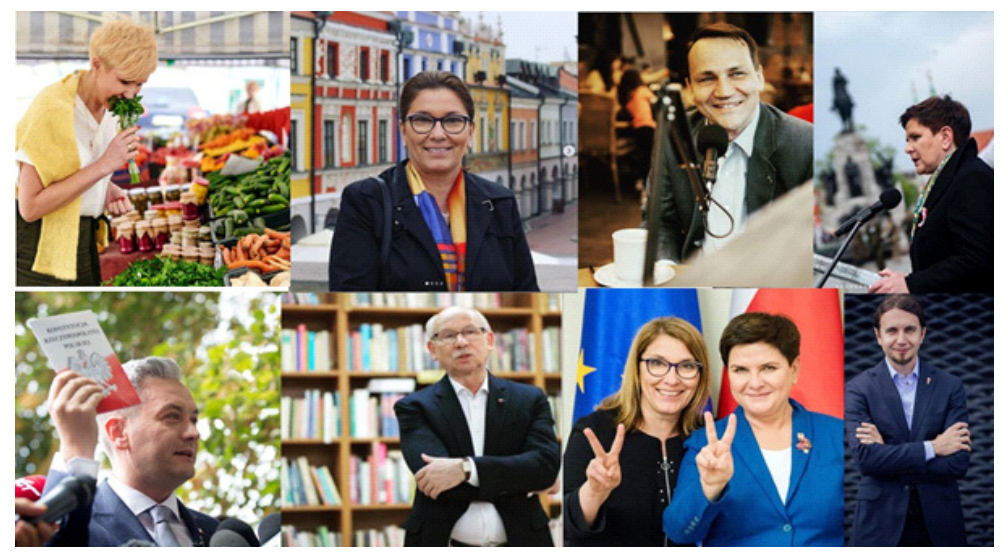

Figure 1. Typical professionally shot self-promotional photos of candidates campaigning (topos of the party nominee) (source: Instagram) 
A similar pattern is seen as regards the profiles of some established politicians, who, depending on their popularity, might complete this official imagery with snapshots of their family or domestic life. A different pattern is championed by challenger politicians, whose private profiles were suddenly adjusted to the purposes of the EP campaign and started featuring more political messages. Only few candidates chose to keep their profiles more private in character throughout the campaign; they rarely updated them (some even decided to suspend them), and presumably used more official and traditional channels to communicate with the voters. In all cases, however, a candidate's Instagram profile was hardly ever open to controversial images or invited confrontation or debate about their political platform. This makes such a strategy of political campaigning reminiscent of personal branding (Borgerson \& Schroeder, 2005) more than public deliberation.

When it comes to correlating Instagram photography with the status of the party, we found that the more established the party, the more professional the output and the more frequent the posting. Even if it is not a surprising finding, we noticed a strong pattern of a candidate's visibility being related to the party visibility, hence little-known candidates from an established party might achieve strategic levels of visibility to ultimately trump well-known politicians from challenger or minority groups.

It can be observed that progressive parties (Spring and The Left) are the most media-savvy in terms of frequency and number of the photos, as well as the styles and technical affordances used. For example, the candidates avoided flooding the profiles with multiple images from one event, kept a balance between private and official posts, used various occasions (e.g., national holidays) to promote their program effectively, engaged with followers through commentary and thank-you posts, and interacted with opponents (which was a strategic manoeuver if the opponents happened to be followed by a larger number of prospective voters). Nevertheless, as could be predicted, the majority of the posts offer "a momentary glance" at political candidates and their symbolic (party) resources, rather than allow for contemplation and critical engagement with their arguments (DeLuca, 2006).

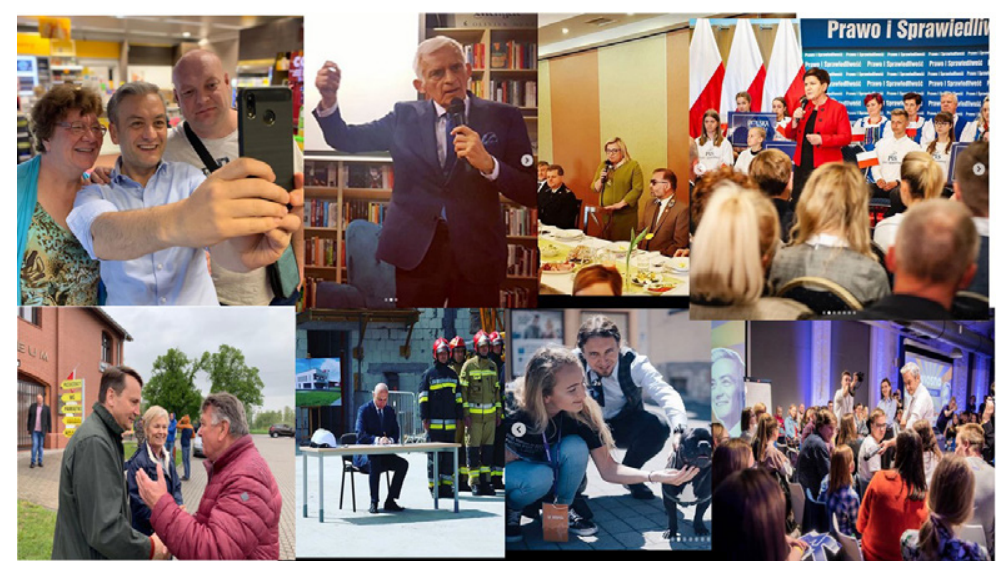

Figure 2. Photos showing candidates "in the field" engaging in interactions and "debate" (topos of the representative) (source: Instagram) 
An analysis of the contents, representations and styles of the photographs leads us to advance several observations on the rhetoric of visual self-promotion. Unsurprisingly, the conventional, even "canonical", photo representation of a campaigning politician is that of a speaker at a rally, with a roomful of people listening or cheering. This is often completed with the imagery of face-to-face encounters with individual voters (Figure 2). The symbolic gesture of the handshake, and of handing something out (e.g., leaflets, flowers, gadgets or cookies), effectively index the politician's open and empathetic attitude towards voters. Such stock photos cumulatively render a positive image of the politician in terms of leadership, generosity and care. We claim that such images contribute to establishing a generic topos of a democratic candidate - a representative of his/her constituents out there in Europe.

Such a candidate may additionally assume a "compassionate" face, when s/he is photographed with the disadvantaged, the elderly or the youth. This resonates with the research on the capacity of conventional or stock photos to activate common associations (Frosh, 2002), and the dominance of pictorial face-ism in promotional material (Borgerson \& Schroeder, 2005). However, the topos of the politician as a protector may be quite misleading, especially in Poland, where politicians tend to be more loyal to their party leadership than to their constituents (Figure 3).

Despite the rhetorical affectivity of photos with vulnerable people around, the preferred company the politicians keep on Instagram are actually fellow party politicians, as if to rely on the collective strength and enthusiasm of the party and campaign teams (Figure 4).

Given the character of the Polish public sphere dominated by party politics, it is noted that even in an EP, the candidates mostly affiliated themselves with national issues and championed domestic policies. Only a few candidates, mostly incumbent members of EP, used EU references and symbols frequently and effectively (cf. Holtz-Bacha et al., 2017). The candidates from the conservative parties (Law and Justice and National Movement) were often photographed in settings involving Polish national symbols. This can be interpreted as a

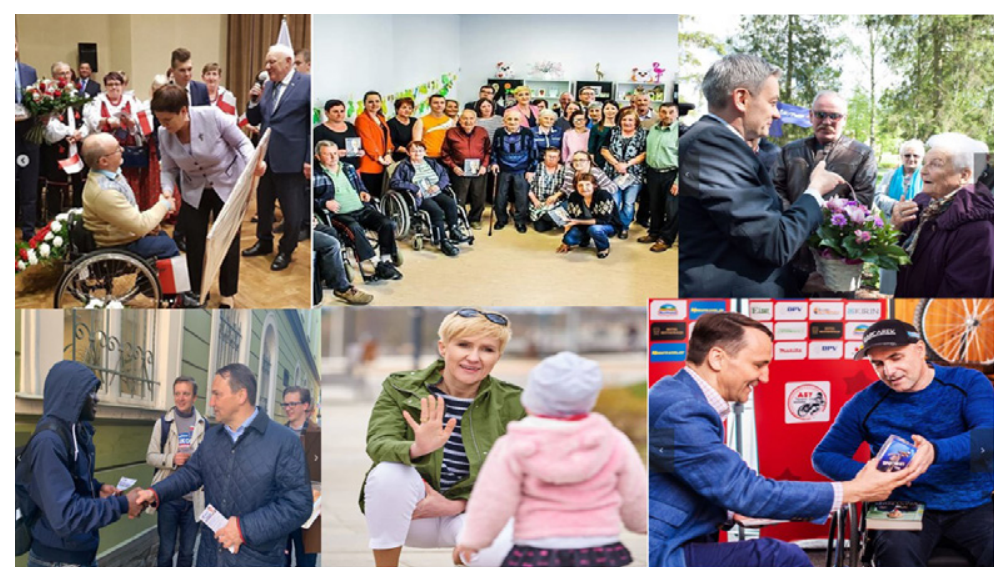

Figure 3. Photos of candidates among "the vulnerable" (topos of the protector) (source: Instagram) 


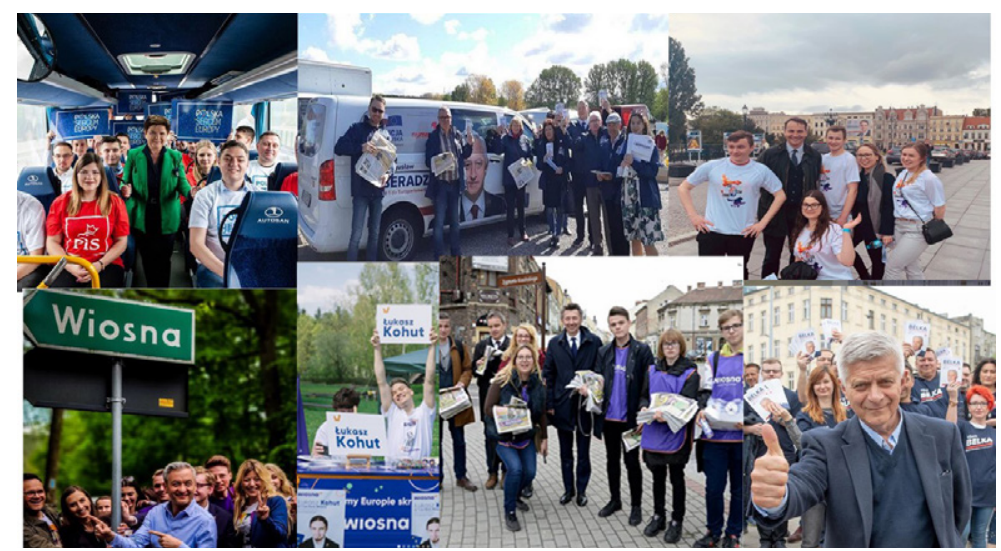

Figure 4. Photos of candidates with "the team"

(topos of the charismatic leader) (source: Instagram)

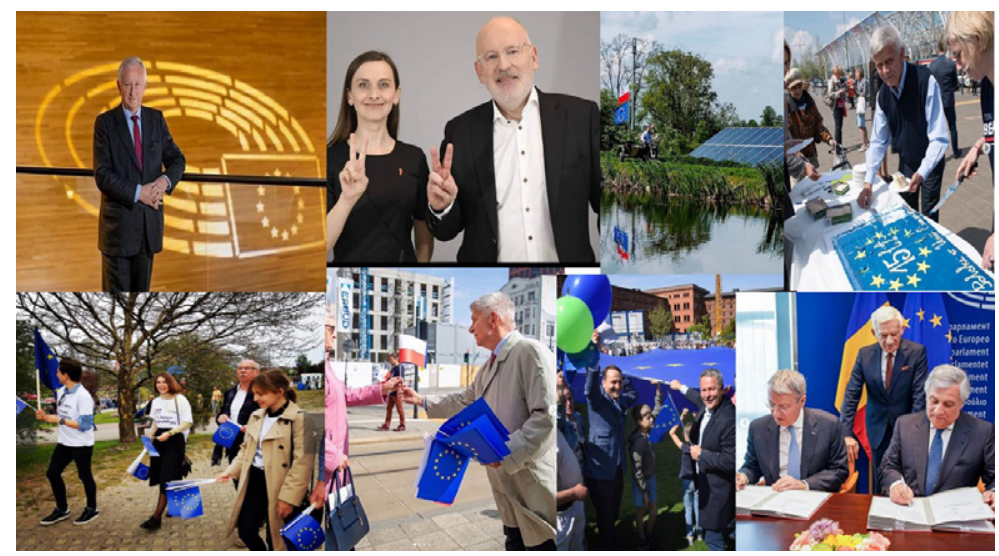

Figure 5. Photos of candidates constructing the notion of belonging and "Europeannes" (topos of the cosmopolitan official) (source: Instagram)

visual manoeuver to represent EU as an antagonist, and themselves as defenders of national interests. Meanwhile, liberal and progressive candidates were more likely to use the topoi of pan-European co-operation and of cosmopolitan solidarity. As the latter values are harder to represent visually, it was common for such candidates to get photographed while participating in the pro-EU street marches and with representatives of various professional groups that benefit from European integration. These two different strategies of self-representation translate into how voters are interpellated visually to identify with the common European polity (Burke, 1969): whereas conservatives foreground the images of Europe as "them", progressives aim to project a more inclusive sense of Europe as "us" (Figure 5).

As is common in political campaigning, candidates strive for prestige and recognition as competent public administrators. To borrow the ethos from institutional authority, the 
incumbent candidates who performed official functions at the time were likely to share photos of themselves engaged in their duties: opening a ceremonial event, handing out subsidies, rewarding distinguished service-people, or participating in cultural festivals including folk people, which were ideal "rhetorical events" for candidates in public office to stage photo-ops (Sheridan et al. 2005). The number of images where candidates performed these duties was probably also intended to show how hard-working they are and to imply that they are going to be equally busy in the EP (cf. "governing by illusions" Erickson, 2000).

\section{Discussion: implications and recommendations}

Visual rhetorical literacy is understood here as one's awareness of means of persuasion and creative inventories, and the willingness to apply critical thinking to all kinds of visual input. A visually literate voter who engages with campaign content through social media that privilege imagery should be aware of its strategic rhetoricity, despite the largely trivial context of e.g., Instagram. Nevertheless, the channel, content, composition, and style of posted photos are likely to be chosen and designed strategically to induce a specific response or attitude, even if they appear reproductive. There are few "innocent" images in political communication, especially in self-promotional campaigning, as they become creatively reconstructed in an effort to produce a desired identification with the candidate or the party.

Secondly, even though the patterns of campaigners' uses of social media have not yet been stabilized (and exploited to the fullest), there are particular functionalities, technical affordances and user preferences that tend to be creatively appropriated to maximize self-promotion. Thus, politicians' profiles are carefully crafted by campaign teams without this being apparent to the followers, who are accustomed to more informal imagery that predominates on Instagram. Images can be selected and designed compositionally or enhanced aesthetically before being posted (Messaris, 2012). For example, well-known symbols, national colors, significant occasions, and typical poses are chosen not only to enhance identification, but also to produce connotations related to authority, leadership, agency or competence. Our examples indicate that EU/national signage, "in-the-crowd" and "on-the-stage" compositions, gaze and hand-shaking gestures as well as slogans embedded in photos are clearly strategic visual manoeuvers.

Thirdly, viewers should be aware that "a picture may be worth a thousand words" when it comes to manufacturing evidentiality on the one hand, and generating desired emotional responses on the other. However, at the same time, the caption or the text in the post (or subsequent critical comments given in response to posted images) can radically alter a glancebased interpretation of the image. The understanding of the rhetorical interplay between meanings in texts and images and of various degrees of commitment to factuality through modality (Ravelli \& van Leeuwen, 2018) are crucial in resisting strategic manoeuvring that aims to enhance poor arguments with flashy images (van Eemeren \& Houtlosser, 1999). For example, on closer inspection, some of the most visually prominent candidates had little to say about their actual action plans at the EP in their posts.

The fourth implication is related to Burkean identification, which can be realized visually, for example through picturing either recognizable locations ("here") or decontextualized set- 
tings ("anywhere") (cf. Machin 2007 on decontextualization or Dan, Arendt 2021 on the ideological role of backdrop cues). Voters tend to identify not only with iconic cultural symbols (flags, emblems, national colors, folk costumes), but also with pictorial schemas drawn from the stock imaginaries of election politics, commercials and mundane snapshots of everyday routines. The persuasiveness of photographs may lie in their ability to foster the sense of "the familiar" through topoi and lead to the impression of communing around common values and emotional needs (e.g., for proper democratic representation, protection, leadership). These affect-laden manoeuvers can help in the identification as "we" - the candidate's followers, the Instagram users, the party supporters. The inescapable analytics of likes, re-posts and other popularity indicators on social media help further entrench social identification and political alignment (with the impression that "we are on the winning side").

Visual persuasion can also result from the uncritical, unreflective consumption of pleasing images in the culture of distraction that encourages ever more media exposure to ideas that are already compatible with our views and aesthetic preferences. Our unwillingness to get exposed to imagery that breaks our stereotypes makes us susceptible to naturalization of one ideology, which actually depoliticizes the voting public and discourages deliberation (Warnick \& Heineman, 2012). Visual rhetorical literacy must recognize a wide range of strategic applications of topoi for the purposes of projecting a semblance of political deliberation. As is the case with stock images treated as topoi in marketing, there are visual and compositional schemas that the campaign team is likely to creatively exploit, such as perspectives (distance/angle) that elevate the candidate, backgrounds that feature certain colors or emblems, accompanying celebrities, or engaging gazes.

\section{Conclusions}

The technical affordances that assist in creating photographs and sharing them instantly through social networks also make it easier than ever to manipulate imagery or produce realistic representations of faked events. It seems unproductive to advocate trainings to spot technical manipulations because it involves special filtering software and an advanced knowledge of information technology (Messaris, 2012). Instead, it might be more useful to equip viewing publics with knowledge and skills and foster dispositions towards visual rhetorical literacy, in other words, to inoculate them (Roozenbeek \& van der Linden, 2019). This is not to say that rhetorical literacy, as any set of human competencies, is a panacea that will dismantle barriers and prevent fraud. In fact, it can also perpetuate inequality between those with and without the cultural capital to acquire it (Young \& Kendall, 2009; Champagne \& Pietarinen, 2020).

However, for one to be a literate visual content consumer, especially in the context of political campaigning, it is important to be aware of the rhetorical devices deployed to persuade with visuals, be they true or fake, artistic or mundane, realistic or manipulated. Visual rhetorical literacy can be cultivated and developed, much like verbal persuasion skills and other cultural and digital literacy practices (Conole \& Dyke, 2004; Livingstone, 2004; Janks, 2010). While one can acquire visual rhetorical literacy, such training cannot be separated from the understanding of larger cultural and aesthetic conventions (topoi) and creative 
inventories in media logics and political rhetorics. With visual rhetorical literacy, researchers or activists would not have to alert voters each time some images advance the interests of communicators in a way that is ethically questionable. The strategic manoeuvring with visual symbols, iconic stock imagery and emotionally-laden representations can be exposed through critical analysis in everyday circumstances. Social media users can reflect on the effectiveness of imagery to mobilize their emotions and their political support. They can also try to assess the aptness (and the ethics) of deploying particular visualization strategies, and the likelihood (if any) of fostering debate and dialogue.

On the other hand, visuals foreground information that verbal political messages tend to background. Both the visual and verbal modes, and the social media technologies that are used to disseminate them, have affordances that can work in tandem to enhance the public sphere rather than dumb it down, as is often suggested (Warnick \& Heineman, 2012). For example, Fenton and Barassi observe that the fact that political and social campaigns have migrated online caused the depoliticizing and fragmenting of the public sphere with "a further push away from a collective public citizenry to isolated, atomized self-hood" (2011, p. 191). The shortage of adequate visual rhetorical literacy might become more acute with the younger generations of voters growing up in the world of snippets, snapshots, slogans and soundbites, for whom Instagram and other social networks would be the principal mode of receiving political information (Messaris, 2012; Seo, 2014). Yet, social media may be an ideal venue for creative reconstruction and promulgation of emotionally based appeals, and thus for mobilization. This was the case with such movements as Me Too movement, Black Lives Matter and other social, environmental and political actions gaining traction due to massive social media campaigning. The awareness of what is being lost and gained in a culture of visual distraction and connectivity is the point for departure for the kind of literacy that truly functions as an "equipment for living".

\section{References}

Borgerson, J. L., \& Schroeder, J. E. (2005). Identity in marketing communications: an ethics of visual representation. In A. J. Kimmel (Ed.), Marketing communication: new approaches, technologies, and styles (pp. 256-277). Oxford University Press.

Burke, K. (1969). A rhetoric of motives. University of California Press.

Champagne, M., \& Pietarinen, A.-V. (2020). Why images cannot be arguments, but moving ones might. Argumentation, 34, 207-236. https://doi.org/10.1007/s10503-019-09484-0

Conole, G., \& Dyke, M. (2004). What are the affordances of information and communication technologies? ALT-J: Research in Learning Technology, 12(2), 113-124.

https://doi.org/10.1080/0968776042000216183

Dan, V., \& Arendt, F. (2021). Visual cues to the hidden agenda: investigating the effects of ideologyrelated visual subtle backdrop cues in political communication. The International Journal of Press/ Politics, 26(1), 22-45. https://doi.org/10.1177/1940161220936593

DeLuca, K. M. (2006). The speed of immanent images: the dangers of reading photographs. In D. S. Hope (Ed.), Visual communication: perception, rhetoric, and technology (pp. 79-90). Papers from the William A. Kern Conferences in Visual Communication. Rochester Institute of Technology. Hampton Press. 
Driessens, O., Raeymaeckers, K., Verstraeten, H., \& Vandenbussche, S. (2010). Personalization according to politicians: A practice theoretical analysis of mediatization. Communications: European Journal of Communication Research, 35(3), 309-326. https://doi.org/10.1515/comm.2010.017

Edwards, J. L. (2012). Visual literacy and visual politics: photojournalism and the 2004 presidential debates. Communication Quarterly, 60(5), 681-697. https://doi.org/10.1080/01463373.2012.725000

Eemeren, van F., Garssen, B., \& Meuffels, B. (2009). Argumentation library: Vol. 16. Fallacies and judgments of reasonableness: empirical research concerning the pragma-dialectical discussion rules. Springer. https://doi.org/10.1007/978-90-481-2614-9

Eemeren, van F. H., \& Houtlosser, P. (1999). Strategic manoeuvring in Argumentative Discourse. Discourse Studies, 1(4), 479-497. https://doi.org/10.1177/1461445699001004005

Erickson, K. V. (2000). Presidential rhetoric's visual turn: performance fragments and the politics of illusionism. Communication Monographs, 67(2), 138-157. https://doi.org/10.1080/03637750009376501

Fenton, N., \& Barassi, V. (2011). Alternative media and social networking sites: the politics of individuation and political participation. The Communication Review, 14(3), 179-196. https://doi.org/10.1080/10714421.2011.597245

Frosh, P. (2002). Rhetorics of the overlooked: on the communicative modes of stock advertising images. Journal of Consumer Culture, 2(2), 171-196. https://doi.org/10.1177/146954050200200202

Holtz-Bacha, Ch., Novelli, E., \& Rafter, K. (Eds.). (2017). Political Advertising in the 2014 European Parliament Elections. Palgrave Macmillan. https://doi.org/10.1057/978-1-137-56981-3

Janks, H. (2010). Literacy and power. In S. Nieto (Ed.), Language, culture, and teaching. Routledge.

Kampka, A., \& Molek-Kozakowska, K. (2020). Instagram w autoprezentacji politycznej. Analiza wizualna postów polskich kandydatów do Europarlamentu w 2019. Polityka i Społeczeństwo, 1(18), 41-62. https://doi.org/10.15584/polispol.2020.1.3

Lehmuskallio, A., Häkkinen, J., \& Seppänen, J. (2019). Photorealistic computer-generated images are difficult to distinguish from digital photographs: a case study with professional photographers and photo-editors. Visual Communication, 18(4), 427-451. https://doi.org/10.1177/1470357218759809

Livingstone, S. (2004). Media literacy and the challenge of new information and communication technologies. The Communication Review, 7(1), 3-14. https://doi.org/10.1080/10714420490280152

Machin, D. (2007). Introduction to multimodal analysis. Hodder Education.

McKeon, R. (1973). Creativity and the commonplace. Philosophy and Rhetoric, 6(4), 199-210.

Messaris, P. (2012). Visual "Literacy" in the digital age. Review of Communication, 12(2), 101-117. https://doi.org/10.1080/15358593.2011.653508

Mourão, R. R., \& Robertson, C. T. (2019). Fake news as discursive integration: an analysis of sites that publish false, misleading, hyperpartisan and sensational information. Journalism Studies, 20(14), 2077-2095. https://doi.org/10.1080/1461670X.2019.1566871

NapoleonCat. (2019). Instagram users in Poland: May 2019. https://napoleoncat.com/stats/instagramusers-in-poland/2019/05

Ott, B. L., \& Dickinson, G. (2009). Visual rhetoric and/as critical pedagogy. In A. A. Lunsford, K. H. Wilson, \& R. A. Eberly (Eds.), The SAGE handbook of rhetorical studies (pp. 391-406). SAGE Publications, Inc. https://oi.org/10.4135/9781412982795.n21

Phillips, K. R. (2018). “The safest hands are our own": Cinematic affect, state cruelty, and the election of Donald J. Trump. Communication and Critical/Cultural Studies, 15(1), 85-89. https://doi.org/10.1080/14791420.2018.1435082

Ravelli, L. J., \& Leeuwen, van Th. (2018). Modality in the digital age. Visual Communication, 17(3), 277-297. https://doi.org/10.1177/1470357218764436 
Roozenbeek, J., \& Linden, van der S. (2019). The fake news game: actively inoculating against the risk of misinformation. Journal of Risk Research, 22(5), 570-580.

https://doi.org/10.1080/13669877.2018.1443491

Seo, H. (2014). Visual propaganda in the age of social media: an empirical analysis of Twitter images during the 2012 Israeli-Hamas conflict. Visual Communication Quarterly, 21(3), 150-161. https://doi.org/10.1080/15551393.2014.955501

Sheridan, D. M., Ridolfo, J., \& Michel, A. J. (2005). The available means of persuasion: mapping a theory and pedagogy of multimodal public rhetoric. Journal of Rhetoric, Culture, and Politics, 2(4), 803-844.

Tuunanen, Y., \& Hirsto, H. (2018). Civic voice in multimodal news narratives. In M. Patrona (Ed.), Crisis and the media: discourse approaches to politics, society and culture (pp. 205-229). John Benjamins Publishing Company. https://doi.org/10.1075/dapsac.76.10tuu

Veneti, A., Jackson, D., \& Lilleker, D. G. (Eds.). (2019). Visual political communication. Palgrave Macmillan. https://doi.org/10.1007/978-3-030-18729-3

Warnick, B., \& Heineman, D. S. (2012). Rhetoric online: the politics of new media. In B. Gronbeck \& M. S. McKinney (General Eds.), Frontiers in political communication: Vol. 22. Peter Lang.

Young, M., \& Kendall, C. (2009). The consequences of rhetoric and literacy: power, persuasion, and pedagogical implications. In A. A. Lunsford, K. H. Wilson, \& R. A. Eberly (Eds.), The SAGE handbook of rhetorical studies (pp. 335-352). SAGE Publications, Inc. https://doi.org/10.4135/9781412982795.n18 